\title{
Mismatch Negativity Elicited by Verbal and Nonverbal Stimuli: Comparison with Potential N1
}

\author{
Mirtes Brückmann ${ }^{10}$ Michele Vargas Garcia² \\ 1 Graduate Program in Disorders of Human Communication, \\ Universidade Federal de Santa Maria (UFSM), Santa Maria, RS, Brazil \\ ${ }^{2}$ Department of Speech-Language Pathology, Universidade Federal \\ de Santa Maria (UFSM), Santa Maria, RS, Brazil
}

Address for correspondence Mirtes Brückmann, Master, Av Roraima, 1000, prédio 26, Bairro Camobi, Santa Maria, SC, CEP: 97105-900, Brazil (e-mail: mirtes.bruckmann@gmail.com).

Int Arch Otorhinolaryngol 2020;24:e154-e159.

\begin{abstract}
\section{Keywords}

- evoked potentials

- auditory

- adult

- hearing

- auditory cortex

Introduction Mismatch negativity (MMN) is a long latency auditory evoked potential, represented by a negative wave, generated after the potential $\mathrm{N} 1$ and visualized in a resulting wave.

Objective To identify the time of occurrence of MMN after N1, elicited with verbal and nonverbal stimuli.

Methods Ninety individuals aged between 18 and 56 years old participated in the study, 39 of whom were male and 51 female, with normal auditory thresholds, at least 8 years of schooling, and who did not present auditory processing complaints. All of them underwent audiologic anamnesis, visual inspection of external auditory meatus, pure tone audiometry, speech audiometry, acoustic immittance measures and the dichotic sentence identification test as a screening for alterations in auditory processing, a requirement to participate in the sample. The MMN was applied with two different stimuli, with these being da/ta (verbal) and $750 \mathrm{~Hz}$ and $1,000 \mathrm{~Hz}$ (nonverbal). Results There was a statistically significant difference between the latency values of the $\mathrm{N} 1$ potential and the MMN with the two stimuli, as well as between the MMN with verbal and nonverbal stimuli, and the latency of the MMN elicited with da/ta being greater than that elicited with $750 \mathrm{~Hz}$ and $1,000 \mathrm{~Hz}$, which facilitated its visualization. Conclusion The time of occurrence of MMN after the $\mathrm{N} 1$ elicited with verbal stimuli was $100.4 \mathrm{~ms}$ and with nonverbal stimuli $85.5 \mathrm{~ms}$. Thus, the marking of the MMN with verbal stimuli proved to be more distant from $\mathrm{N} 1$ compared with the nonverbal stimuli.
\end{abstract}

\section{Introduction}

Among the auditory evoked potentials, there are long latency potentials, also called cortical and/or cognitive potentials, that evaluate the neuroelectric activity in the cerebral cortex, in response to an acoustic or electrical stimulus. ${ }^{1,2}$ These potentials are most commonly used to evaluate auditory abilities objectively. ${ }^{3-5}$

The long latency auditory evoked potential (LLAEP) record shows a sequence of negative $(\mathrm{N})$ and positive $(\mathrm{P})$ peaks, among which are the potential P1-N1-P2-N2-P300 and mismatch negativity (MMN). The P1-N1-P2 complex represent the corti-

received

August 11, 2018

accepted

July 3, 2019
DOI https://doi.org/

10.1055/s-0039-1696701. ISSN $1809-9777$. cal potentials and provide information on the arrival on the auditory stimuli to the cortex. ${ }^{6}$ The potential $\mathrm{N} 2$ is considered a mixed potential, and the P300, a cognitive potential that depends on the attention of the subject to be elicited. ${ }^{7}$

The MMN is a LLAEP represented by a negative wave generated after the potential $\mathrm{N} 1$ and visualized in a resulting wave. $^{8}$ This potential is elicited passively, and it is not necessary for the individual to pay attention to the sound stimuli; $;{ }^{9} 10$ it arises when the cortex automatically discriminates between two different sound stimuli, based on their already acquired sound memory. ${ }^{11-13}$

Copyright @ 2020 by Thieme Revinter

Publicações Ltda, Rio de Janeiro, Brazil

License terms

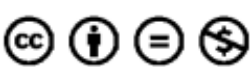


This potential has its main origin in the auditory cortex, but depending on the characteristics of the stimuli used, it can be generated in different places of the cortex, ${ }^{12,14,15}$ or in the frontal cortex, thalamus, and hippocampus. ${ }^{16}$ Mismatch negativity elicited by stimuli that differ in frequency can be generated in the temporal and frontal lobes, especially in the right hemisphere. ${ }^{14}$ The MMN elicited by verbal stimuli originates in the left hemisphere of the temporal cortex. ${ }^{17}$

Mismatch negativity is a good tool to perform an objective evaluation in patients with difficulty or impairment in communication, or those whose auditory discrimination is under investigation. ${ }^{18}$ When using verbal stimuli in an evaluation, for example, this potential may complement the behavioral evaluation that may not be sufficient in some cases for cognitive or linguistic reasons, as they provide additional information about the biological processes involved in speech processing. In addition, this information may direct the rehabilitation and therapeutic follow-up of the individual. ${ }^{19,20}$

However, Brazilian researchers rarely use this potential, further reducing their chances of participating in clinical evaluation, which may be due to the fact that it is a potential with a certain "difficulty" to be analyzed, considering the parameters of registration, equipment and age of the evaluated individuals, this may cause a variation in the identification of the valley. Therefore, there is a need for better details of both the recording parameters and stimuli, as well as the potential marking technique, which is little explored in the studies already performed. Therefore, the objective of this study is to identify the time of occurrence of MMN after N1, elicited with verbal and nonverbal stimuli.

\section{Method}

This is an observational and descriptive study, with a convenience sample, which was approved by the Human Research Ethics Committee, under the number CAAE 54827416.5.0000.5346. The study followed the principles of beneficence established through resolutions $466 / 12^{21}$ and $510 / 16 .^{22}$ All individuals invited to participate in the study were informed about the procedures and, after acceptance, all of them signed the informed consent form.

Adult subjects aged between 18 and 59 years old of both genders were invited to participate in this research. This population was chosen because there are not many studies on the parameters of MMN in this age group in the SmartEP equipment (Intelligent Hearing Systems, Miami, FL, USA) yet. Also, we chose not to divide the sample into different age groups, since, according to one study, ${ }^{23}$ which compared adult individuals aged between 18 and 24 years with elderly individuals between 60 and 80 years, there was no difference in the latency and amplitude of MMN for these age groups. Another study, ${ }^{24}$ that evaluated individuals aged between 18 and 80 years, only observed a decrease in amplitude with increasing age. However, the authors evaluated a group of more advanced age than that of the group in the current study, which could justify this result. These facts allow the justification of non-segregation of the sample in the current study in different age groups.
To participate in the survey, volunteers should meet the following eligibility criteria: auditory thresholds up to 25 dBHL in frequencies from 250 to $8,000 \mathrm{~Hz}$ bilaterally; minimum of eight years of schooling (complete elementary education); have no external and middle ear alterations identified by tympanometry; have no history of head injury and/or stroke; did not have evident neurological or psychiatric alterations and presented values of normality in the dichotic sentence identification (DSI) test, ${ }^{25}$ which served as a screening for auditory processing alterations.

Therefore, all subjects first underwent audiological anamnesis, visual inspection of the external auditory meatus, pure tone audiometry, speech audiometry, acoustic immittance measures and DSI, and those who fulfilled the study criteria, performed, finally, the MMN with two different stimuli (verbal and nonverbal). Based on these evaluations, the sample comprised 90 subjects aged between 18 and 56 years old, with 39 being male and 51 being female.

The pure tone audiometry, the speech audiometry and the DSI were performed in an acoustically treated cabin, using Telephonics brand earphones TDH-39P (Telephonics, Farmingdale, NY, USA), and Otometrics brand audiometer Itera II model (Natus Medical Inc., Schaumburg, IL, USA). For the acoustic immittance measures, an Interacoustics brand immittanciometer AT 235 model (Interacoustics, Middelfart, Denmark) was used, and only those individuals who presented tympanometric curve of type "A" were admitted. ${ }^{26}$

The MMN potential was performed with the two channel SmartEP equipment (Intelligent Hearing Systems), following a record protocol suggested by the literature ${ }^{8}$ in LLAEP measurement equipment, regarding the type of paradigm (oddball); contrast of frequency stimuli $(750 \mathrm{~Hz}$ and $1,000 \mathrm{~Hz}$ ); probability of occurrence of rare stimuli (20\%); number of different stimuli on average (minimum of 150 ); filters $(1-30 \mathrm{~Hz})$; type of stimulation (binaural via insertion earphones); condition of the subject during recording (seated, watching a subtitled movie without sound), and recording window (512 ms with $50 \mathrm{~ms}$ prior to stimulation). This prestimulation is suggested by some authors to make a measurement of the noise level before the beginning of the stimulation and also for the formation of the baseline. ${ }^{27-29}$

The electrodes were positioned in the participants according to the standards of the International Electrode System $10-20 .{ }^{30}$ In the Fz position, the active electrode; in $\mathrm{Fpz}$, the ground electrode and in the right and left mastoid the reference electrodes. The impedance was maintained at a level equal to or less than $3 \mathrm{kOhms}$.

Before placing the electrodes, the skin was cleansed with the aid of an exfoliating gel, and an electrolytic paste was used for the placement of the electrodes, which were fixed with micropore tape in the indicated regions. The participants were instructed to remain as quiet as possible and pay attention only to the movie, trying to ignore the acoustic stimuli received by the earphone. $8,9,27,31$

Mismatch negativity was searched with two pairs of stimuli, one consisting of verbal stimuli (da/ta) and the other by nonverbal stimuli $(750 \mathrm{~Hz}$ and $1,000 \mathrm{~Hz})$. For all the subjects, 
the same order of presentation of the stimuli was followed, the nonverbal was first presented and then the verbal stimuli.

Speech stimuli are synthetic, not natural, and were produced by the SmartEP- Intelligent Hearing Systems. All the stimuli used were presented in alternating polarity and had durations of $5 \mathrm{~ms}$ for $750 \mathrm{~Hz} ; 10 \mathrm{~ms}$ for $1,000 \mathrm{~Hz} ; 206.2 \mathrm{~ms}$ for /da/, and $220.3 \mathrm{~ms}$ for the syllable /ta/. The velocity was 1.9 stimuli per second. ${ }^{32}$ The total number of stimuli presented was 750 , of which 150 were rare stimuli, as suggested by the literature. ${ }^{8,9,33}$ The artifacts were controlled to not exceed $10 \%$ of the number of rare stimuli. ${ }^{34}$

The intensity used was $60 \mathrm{dBnHL}$ for the verbal stimuli and $70 \mathrm{dBnHL}$ for the nonverbal, because when performing the MMN in 5 speech therapists who acted as judges in this criterion before starting the study, they verified that there was a difference in perception of intensity between the verbal and nonverbal stimuli, making necessary the application of different intensities, to leave the sense of equivalence as close as possible.

The MMN of all the subjects was captured and visualized on the computer to which the equipment was coupled, and then the latency of the valley was recorded, which was considered the most negative peak, ${ }^{33,35-37}$ present in the resulting pattern, obtained by the subtraction between the waves of response to the frequent stimuli and responses to the rare stimuli. ${ }^{16,28,32,38,39}$ Also, only MMNs were considered as the potential ones that occurred after N1, which was represented in the pattern of the frequent stimuli, as suggested by the literature, ${ }^{8,40}$ and only the valleys that were visualized in a latency up to $300 \mathrm{~ms}^{39,41,42}$

In the statistical analysis, the paired Student $t$-test was used to compare the means of $\mathrm{N} 1$ latency and MMN latency in each stimulus, and the analysis of variance (ANOVA) test was used to compare the difference found between the latencies of the potentials, with the different stimuli. Significant results were considered when $p \leq 0.05$ with a $95 \%$ confidence interval.

\section{Results}

- Table 1 compares the latency found in the potential N1, visualized in the pattern of the frequent stimuli, with the latency found in the MMN potential, visualized in the pattern of the resulting wave, both verbal and nonverbal stimuli, according to their averages. A significant result is observed for the two stimuli, showing that there is difference between the two latencies, and that the MMN presented different latency means, which does not occur with N1.
Table 2 Comparison of difference of latency between N1 and mismatch negativity elicited with different stimuli

\begin{tabular}{|l|l|l|}
\hline Difference N1-Lat. & MMN da/ta & $\begin{array}{l}\text { MMN 750 Hz } \\
\text { and 1,000 Hz }\end{array}$ \\
\hline Average & 100.4 & 85.5 \\
\hline Median & 118.0 & 79.0 \\
\hline Standard deviation & 55.4 & 44.6 \\
\hline CV & $55 \%$ & $52 \%$ \\
\hline Min & 209.0 & 210.0 \\
\hline Max & 17.0 & 19.0 \\
\hline N & 78 & 73 \\
\hline Cl & 8.7 & 7.2 \\
\hline p-value & & \\
\hline
\end{tabular}

Legend: $\mathrm{Cl}$, confidence interval; $\mathrm{CV}$, coefficient of variation; Lat., latency; MMN, mismatch negativity; Min, minimum; Max, maximum; N, number of subjects.

${ }^{\mathrm{a} A n a l y s i s ~ o f ~ v a r i a n c e ~ t e s t . ~}$

Then, - Table 2 shows the comparison of latency mean of the difference between the two potentials, according to the sound stimulus used (verbal and nonverbal). It is possible to observe a statistically significant difference for latencies, wherein the verbal stimulus elicits a later MMN in relation to the N1, when observing the mean of the two stimuli.

Also, for clarity and understanding about the marking of potentials, a pattern performed with the da/ta stimuli is demonstrated in - Fig. 1, and with stimuli of $750 \mathrm{~Hz}$ and $1,000 \mathrm{~Hz}$ in - Fig. 2 .

\section{Discussion}

In - Tables $\mathbf{1}$ and 2, it can be observed that of the 90 participants, 78 elicited the MMN potential with the da/ta stimuli, and 73 with the $750 \mathrm{~Hz}$ and $1,000 \mathrm{~Hz}$ stimuli, demonstrating that the verbal stimuli were able to elicit a larger number of MMN, in the same individuals. It is not possible to know exactly what caused potential absences in some participants, but it is believed that this may have occurred because of some factors, such as attention to sound that has impaired the capture of the MMN and, thus, have demonstrated another representation of the discrimination of the stimuli; also by the methodology adopted, which did not consider MMN the valleys above $300 \mathrm{~ms}$; and even by changes not captured by

Table 1 Comparison between the average latency of N1 and the average latency of the mismatch negativity elicited with verbal and nonverbal stimuli

\begin{tabular}{|l|l|l|l|l|l|l|l|l|l|l|}
\hline & Latency & Average & Median & Standard deviation & CV & Min & Max & N & Cl & $p$-value \\
\hline \multirow{2}{*}{ da/ta } & N1 & 111.6 & 110.0 & 13.1 & $12 \%$ & 76.0 & 137.0 & 78 & 2.1 & $<0.001$ \\
\cline { 2 - 10 } & MMN & 211.9 & 233.0 & 56.3 & $27 \%$ & 100.0 & 299.0 & 78 & 8.8 & \\
\hline \multirow{2}{*}{$750 \mathrm{~Hz}$ and $1,000 \mathrm{~Hz}$} & $\mathrm{~N} 1$ & 100.4 & 101.0 & 15.7 & $16 \%$ & 71.0 & 134.0 & 73 & 2.5 & $<0.001$ \\
\cline { 2 - 9 } & $\mathrm{MMN}$ & 185.8 & 177.0 & 45.7 & $25 \%$ & 100.0 & 298.0 & 73 & 7.4 & \\
\hline
\end{tabular}

Legend: $\mathrm{Cl}$, confidence interval; $\mathrm{CV}$, coefficient of variation; Lat., latency; Min., minimum; Max., maximum; MMN, mismatch negativity; $\mathrm{N}$, number of subjects. T-Student test. 


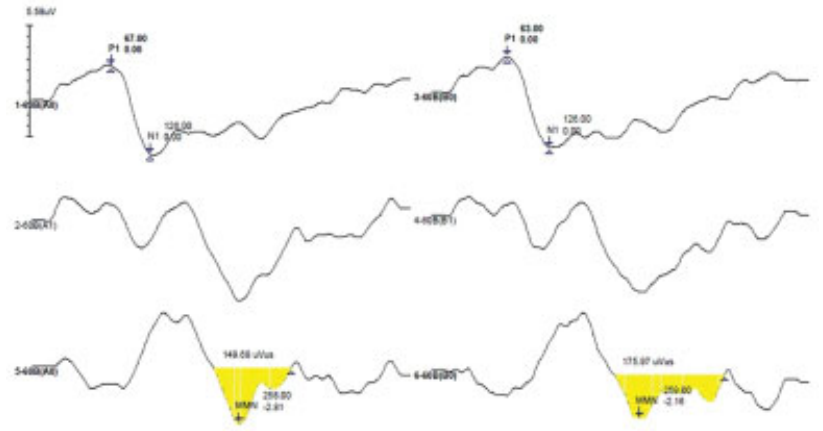

Fig. 1 Example of mismatch negativity marking elicited with the verbal stimuli da/ta.

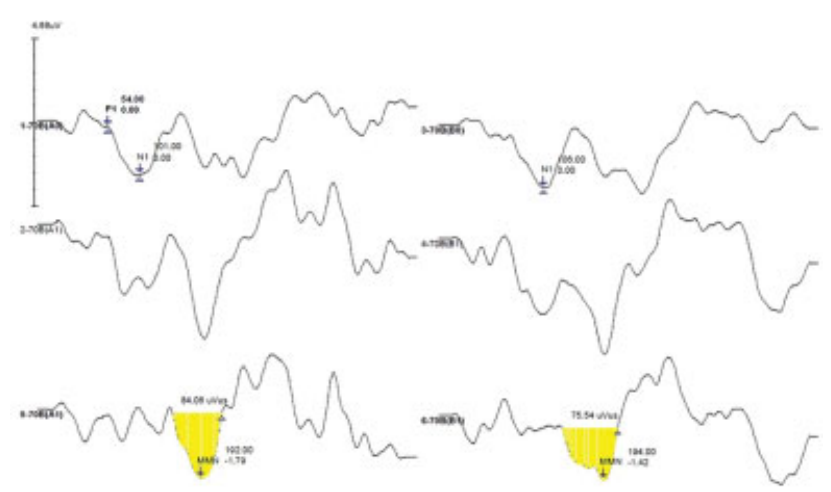

Fig. 2 Example of mismatch negativity marking elicited with nonverbal stimuli of $750 \mathrm{~Hz}$ and $1,000 \mathrm{~Hz}$.

the behavioral tests, but that can be captured by the MMN as already evidenced by another study. ${ }^{43}$

As for the greater number of individuals eliciting the MMN with the da/ta stimulus, it is believed that it may have occurred by the different brain response sites for the stimuli, because although this potential has its main origin in the cortex, the MMN elicited by stimuli that differ in frequency can be generated in the temporal and frontal lobes, mainly in the right hemisphere, ${ }^{14}$ and, when elicited by verbal stimuli, the MMN are usually originated in the left hemisphere of the temporal cortex. ${ }^{17}$

Further, - Table 1 also shows a statistically significant difference between N1 and MMN latencies for both verbal and nonverbal stimuli, with da/ta being the stimuli that provoked a higher latency in the potential, showing a statistically significant difference in relation to the stimulus of $750 \mathrm{~Hz}$ and $1,000 \mathrm{~Hz}$, as shown in - Table 2. This data can also be clearly perceived when comparing - Figs. 1 and $\mathbf{2}$.

The fact that there was a higher latency for the verbal stimuli, when compared with a nonverbal one, has also been observed in another study with LLAEP; however, it was for the P300 potential. The authors suggest that latency is sensitive to the task processing demand, and in the case of verbal stimuli, as they demand a more complex listening when compared with the discrimination of nonverbal stimuli, they cause an increase in their latency. ${ }^{20}$

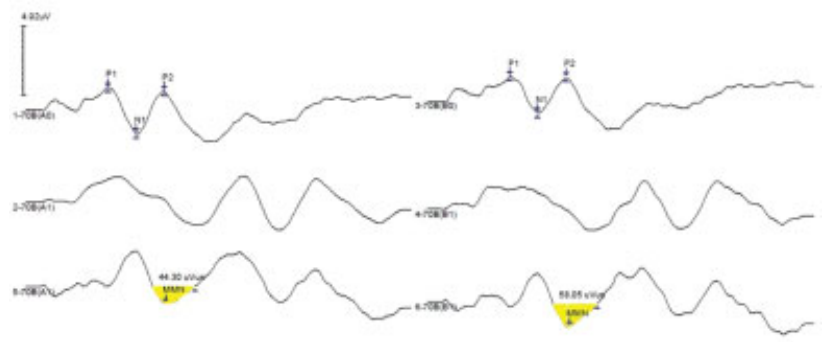

Fig. 3 Example of mismatch negativity marking elicited with nonverbal stimuli of $750 \mathrm{~Hz}$ and $1,000 \mathrm{~Hz}$ with the presence of two negative valleys in the resulting wave.

Still in relation to the stimuli of da/ta, as the participants needed to keep their attention focused on another activity (to watch a movie), and not in the auditory stimuli while they were evaluated, they reported that it was more difficult not to pay attention to the verbal sound stimuli, which was already expected due to the difference in sensation, being greater for the verbal stimuli, even at a lower intensity than the nonverbal one, due to the linguistic load that this type of stimuli presents, being a speech sound and being part of the routine of the subjects. This information further highlights the need for the use of low-contrast stimuli, as reported in the literature, ${ }^{11,27,44}$ since the more subtle differences allow the evaluated subject to maintain attention in the desired activity, such as watching a movie, and not on the sound stimuli, thus making the response of potential more present and reliable. However, even with these reports, it was the stimuli of the da/ta that elicited most of the MMN, reinforcing the idea that the site of brain response may have influenced. ${ }^{14}$

The valleys marked in the patterns of this study were those that fit within the latency stipulated in the methodology, even if there was the presence of another negative

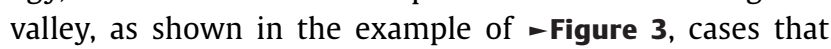
are often cause of doubts at the moment of potential marking. There was also no retest in the subjects who did not present MMN, or replication to confirm the potential, since this could cause fatigue, and it was verified that the muscular tension of sitting for a long time interfered in the pattern, as well as in the MMN capture, which remained compromised in those subjects who took the test with sleep, since they were instructed not to sleep and watch the movie without sound.

Regarding the average latency found, this study agrees with the results already obtained in another research ${ }^{41}$ regarding the nonverbal stimuli, in which a mean latency of $193.13 \mathrm{~ms}$ was observed for different frequencies; in the current study, similar results were found, with a mean latency of $185.8 \mathrm{~ms}$. Also, the study cited used nonverbal stimuli that differed in duration and found an even greater value, that being $230.63 \mathrm{~ms}$. Thus, it is observed that there are differences in latencies of the potentials according to the characteristics of the stimuli, since even though they were two nonverbal stimuli, they presented different latency values, which reinforces the idea that each exam should be carefully analyzed, since several factors influence the results, 
such as equipment and type of stimuli, that should interfere in the correct marking of the potential.

The mean latency found in the da/ta and $750 \mathrm{~Hz}$ and $1,000 \mathrm{~Hz}$ stimuli was observed where traditionally the MMN valley is found, as already mentioned in many studies with these and other types of stimuli, which is between 100 and 250 ms or between 150 and 275 ms. 5,6,13,29,37,45,46 However, it is observed in - Table 1 that the minimum value found for the two stimuli are in agreement with the literature and the maximum value a little beyond the already reported values. This fact can be due to the differences that exist between the multiple equipments that exist in the market.

The greatest evidence that this study wanted to demonstrate was the time of occurrence of MMN after N1, to help in the marking of this potential and encourage the inclusion of it in the clinical routine. Therefore, to obtain this mean value of difference between the two potentials, the comparison shown in -Table $\mathbf{2}$ was performed, so that it can be used as a guide when marking the MMN according to the type of stimuli to be used. Therefore, according to this analysis, the marking of the wave elicited by the da/ta stimuli will occur generally around $100.4 \mathrm{~ms}$ after $\mathrm{N} 1$ and, around $85.5 \mathrm{~ms}$ after $\mathrm{N} 1$ when elicited by $750 \mathrm{~Hz}$ and $1,000 \mathrm{~Hz}$ in the SmartEP equipment. This greater difference with the verbal stimulus is justified by the fact that MMN occurs later when this type of stimulus is used, as already mentioned. The difference in the acoustic pattern for verbal and non-verbal stimuli suggests that the processing of these two types of stimuli by the central auditory nervous system occur differently. ${ }^{14,36}$

\section{Conclusion}

The time of occurrence of MMN after the N1 elicited with verbal stimuli was $100.4 \mathrm{~ms}$ and with nonverbal stimuli, it was $85.5 \mathrm{~ms}$. Thus, the marking of the MMN with verbal stimuli proved to be more distant from N1 compared with the nonverbal stimuli.

\section{Contribution of authors}

\section{Conflict of interest}

The authors declare that there are no conflicts of interest.

\section{References}

1 Purdy SC, Kelly AS, Thorne PR. Auditory evoked potentials as measures of plasticity in humans. Audiol Neurotol 2001;6(04):211-215

2 Junqueira CAO, Colafêmina JF. Investigação da estabilidade inter e intra-examinador na identificação do P300 auditivo: análise de erros. Rev Bras Otorrinolaringol 2002;68(04):468-478

3 Regaçone SF, Gução ACB, Giacheti CM, Romero ACL, Frizzo ACF. Potenciais evocados auditivos de longa latência em escolares com transtornos específicos de aprendizagem. Audiol Commun Res 2014;19(01):13-18

4 Reis ACMB, Frizzo ACF, Isaac ML, Garcia CFD, Funayama CAR, Iório MCM. P300 em indivíduos com perda auditiva sensorioneural. Rev Bras Otorrinolaringol (Engl Ed) 2015;81(02):126-132

5 Schwade LF, Didoné DD, Sleifer P. Auditory Evoked Potential Mismatch Negativity in Normal-Hearing Adults. Int Arch Otorhinolaryngol 2017;21(03):232-238
6 Martin BA, Tremblay KL, Stapells DR. Principles and applications of cortical auditory evoked potentials. In: Burkard RF, Don M, Eggermont JJ (Orgs.). Auditory evoked potentials: basic principles and clinical application. Baltimore: Lippincott Williams \& Wilkins; 2007:483-507

7 Reis ACMB, Frizzo ACF. Potencial Evocado Auditivo de Longa Latência. In: Bevilacqua MC, Martinez MAN, Balen AS, Pupo AC, Reis ACMB, Frota S. Tratado de audiologia. São Paulo: Santos; 2012:231-60

8 Roggia SM. Mismatch Negativity (MMN). In: Boechat EM, Menezes PL, Couto CM, Frizzo ACF, Scharlach RC, Anastasio ART. Tratado de Audiologia. Rio de Janeiro: Guanabara Koogan; 2015:151-9

9 Duncan CC, Barry RJ, Connolly JF, et al. Event-related potentials in clinical research: guidelines for eliciting, recording, and quantifying mismatch negativity, P300, and N400. Clin Neurophysiol 2009;120(11):1883-1908

10 Sussman ES, Chen S, Sussman-Fort J, Dinces E. The five myths of MMN: redefining how to use MMN in basic and clinical research. Brain Topogr 2014;27(04):553-564

11 Näätänen R, Gaillard AWK, Mäntysalo S. Early selective-attention effect on evoked potential reinterpreted. Acta Psychol (Amst) 1978;42(04):313-329

12 Picton TW, Alain C, Otten L, Ritter W, Achim A. Mismatch negativity: different water in the same river. Audiol Neurotol 2000;5(3-4):111-139

13 Näätänen R, Paavilainen P, Rinne T, Alho K. The mismatch negativity (MMN) in basic research of central auditory processing: a review. Clin Neurophysiol 2007;118(12):2544-2590

14 Näätänen R. Attention and Brain Function. Hillsdale, NJ: Lawrence Erlbaum Associates; 1992

15 Kraus N, McGee T, Carrell TD, Sharma A. Neurophysiologic bases of speech discrimination. Ear Hear 1995;16(01):19-37

16 Näätänen R, Astikainen P, Ruusuvirta T, Huotilainen M. Automatic auditory intelligence: an expression of the sensory-cognitive core of cognitive processes. Brain Res Brain Res Rev 2010;64(01): 123-136

17 Kujala A, Alho K, Service E, Ilmoniemi RJ, Connolly JF. Activation in the anterior left auditory cortex associated with phonological analysis of speech input: localization of the phonological mismatch negativity response with MEG. Brain Res Cogn Brain Res 2004;21(01):106-113

18 Brossi AB, Borba KC, Garcia CFD, Reis ACMB, Isaac ML. Verificação das respostas do mismatch negativity (MMN) em sujeitos adultos normais. Rev Bras Otorrinolaringol 2007;73(06):793-802

19 Oates PA, Kurtzberg D, Stapells DR. Effects of sensorineural hearing loss on cortical event-related potential and behavioral measures of speech-sound processing. Ear Hear 2002;23(05):399-415

20 Massa CGP, Rabelo CM, Matas CG, Schochat E, Samelli AG. P300 with verbal and nonverbal stimuli in normal hearing adults. Rev Bras Otorrinolaringol (Engl Ed) 2011;77(06):686-690

21 MINISTÉRIO DA SAÚDE. Resolução $n^{\circ}$ 466, de 12 de dezembro de 2012. Incorpora, sob a ótica do indivíduo e das coletividades, os referenciais da bioética, autonomia, não maleficência, beneficência, justiça e equidade, dentre outros, e visa a assegurar os direitos e deveres que dizem respeito aos participantes da pesquisa, à comunidade científica e ao Estado. Conselho Nacional de Saúde, Brasília, DF, 14 jun. 2013. Disponível em: http://conselho.saude. gov.br/ultimas_noticias/2013/06_jun_14_publicada_resolucao. html. Acesso em 25 abr. 2017.

22 CONSELHO NACIONAL DE SAÚDE. Resolução 510 de 07 de abril de 2016. Trata das especificidades éticas das pesquisas nas ciências humanas e sociais e de outras que utilizam metodologias próprias dessas áreas. Conselho Nacional de Saúde, Brasília, DF, 07 abr. 2016. Disponível em: http://conselho.saude.gov.br/resolucoes/ 2016/reso510.pdf. Acesso em 13 dez. 2017.

23 Buranelli G, Barbosa MB, Garcia CFD, et al. Verificação das respostas do Mismatch Negativity (MMN) em sujeitos idosos. Rev Bras Otorrinolaringol (Engl Ed) 2009;75(06):831-838 
24 Schiff S, Valenti P, Andrea P, et al. The effect of aging on auditory components of event-related brain potentials. Clin Neurophysiol 2008;119(08):1795-1802

25 Andrade NA, Gil D, Iório MCM. Valores de referência para o teste de identificação de sentenças dicóticas em português brasileiro segundo orelha e idade. Rev Bras Otorrinolaringol (Engl Ed) 2015; 81(05):459-465

26 Jerger J. Clinical experience with impedance audiometry. Arch Otolaryngol 1970;92(04):311-324

27 Lang AH, Eerola O, Korpilahti P, Holopainen I, Salo S, Aaltonen O. Practical issues in the clinical application of mismatch negativity. Ear Hear 1995;16(01):118-130

28 Cranford JL, Walker LJ, Stuart A, Elangovan S, Pravica D. Potential contamination effects of neuronal refractoriness on the speechevoked mismatch negativity response. J Am Acad Audiol 2003;14 (05):251-259

29 Takegata R, Mariotto Roggia S, Näätänen R. A paradigm to measure mismatch negativity responses to phonetic and acoustic changes in parallel. Audiol Neurotol 2003;8(04):234-241

$30 \mathrm{Klem} \mathrm{GH}$, Lüders $\mathrm{HO}$, Jasper $\mathrm{HH}$, Elger C; The International Federation of Clinical Neurophysiology. The ten-twenty electrode system of the International Federation. Electroencephalogr Clin Neurophysiol Suppl 1999;52:3-6

31 Sinkkonen J, Tervaniemi M. Towards optimal recording and analysis of the mismatch negativity. Audiol Neurotol 2000;5(3-4):235-246

32 Shankarnarayan VC, Maruthy S. Mismatch negativity in children with dyslexia speaking Indian languages. Behav Brain Funct 2007;3 (36):36

33 Roggia SM, Colares NT. O Mismatch Negativity em pacientes com distúrbios do processamento auditivo (central). Rev Bras Otorrinolaringol (Engl Ed) 2008;74(05):705-711

34 Sousa LCA, Piza MRT, Alvarenga KF, Coser PL. Eletrofisiologia da Audição e Emissões Otoacústicas: princípios e aplicações clínicas. São Paulo: Tecmedd; 2008

35 Korpilahti P, Krause CM, Holopainen I, Lang AH. Early and late mismatch negativity elicited by words and speech-like stimuli in children. Brain Lang 2001;76(03):332-339
36 Näätänen R, Pakarinen S, Rinne T, Takegata R. The mismatch negativity (MMN): towards the optimal paradigm. Clin Neurophysiol 2004;115(01):140-144

37 Pakarinen S, Teinonen T, Shestakova A, et al. Fast parametric evaluation of central speech-sound processing with mismatch negativity (MMN). Int J Psychophysiol 2013;87(01):103-110

38 Morr ML, Shafer VL, Kreuzer JA, Kurtzberg D. Maturation of mismatch negativity in typically developing infants and preschool children. Ear Hear 2002;23(02):118-136

39 Cai Y,Zheng Y, Liang M, et al. Auditory Spatial Discrimination and the Mismatch Negativity Response in Hearing-Impaired Individuals. PLoS One 2015;10(08):e0136299

40 Bishop DV. Using mismatch negativity to study central auditory processing in developmental language and literacy impairments: where are we, and where should we be going? Psychol Bull 2007; 133(04):651-672

41 Kärgel C, Sartory G, Kariofillis D, Wiltfang J, Müller BW. Mismatch negativity latency and cognitive function in schizophrenia. PLoS One 2014;9(04):e84536

42 Choudhury NA, Parascando JA, Benasich AA. Effects of Presentation Rate and Attention on Auditory Discrimination: A Comparison of Long-Latency Auditory Evoked Potentials in School-Aged Children and Adults. PLoS One 2015;10(09):e0138160

43 Bertoli S, Smurzynski J, Probst R. Temporal resolution in young and elderly subjects as measured by mismatch negativity and a psychoacoustic gap detection task. Clin Neurophysiol 2002;113 (03):396-406

44 Sanju HK, Kumar P. Comparison of Pre-Attentive Auditory Discrimination at Gross and Fine Difference between Auditory Stimuli. Int Arch Otorhinolaryngol 2016;20(04):305-309

45 Kraus N, McGee T. Potenciais auditivos de longa latência. In: Katz J. Tratado de audiologia clínica. São Paulo: Manole; 1999: 403-20

46 Schaadt G, Pannekamp A, Meer EVD. Gaining mismatch negativity! Improving auditory phoneme discrimination by literacy training A pre-post event-related potential study. Int J Sch Cogn Psychol 2014;1(101): 